\title{
Monitoring the Effect of Different Storage Conditions of Cold-Pressed Rice Bran Oil
}

\author{
Chutima Ponchurdchai and Jirada Singkhonrat
}

\begin{abstract}
This study investigated the effect of different storage conditions of cold-pressed rice bran oil from 2 different regions in Thailand (Lopburi province, LRBO and Yasothorn province, YRBO). All samples were stored at different temperature as opened and sealed bottle for 12 months. Fatty acid composition by nuclear magnetic resonance, NMR spectroscopy, chemical properties such as acid value, iodine value and peroxide value were reported. Also, the antioxidant content and its activity were evaluated, including FRAP assay (Ferric reducing antioxidant potential) and DPPH radical scavenging assay (1, 1-diphenyl-2-picrylhydrazyl radical reducing power methods). Cold-pressed rice bran oils sealed bottles for 12 months and freshly opened bottles have shown no affect to acid value, iodine value and peroxide value $(p<0.05)$. Fatty acid composition of oil by ${ }^{1} \mathrm{H}$ NMR technique obtained a good agreement with gas chromatography technique and observed mol\% of unsaturated fatty acid was slightly decreased after year storage. After 12-month storage below $5^{\circ} \mathrm{C}$ temperature, LRBO and YRBO showed good radical scavenging activities compared to quercetin with $\mathrm{DPPH} \mathrm{IC}_{50}$ of $0.647 \pm 0.02$ and $0.663 \pm 0.02 \mathrm{mg} / \mathrm{mL}$ and with FRAP assay of $0.42106 \pm 0.002$ and $0.37471 \pm 0.002$ g quercetin equivalents $/ g$, respectively.
\end{abstract}

Index Terms-Rice bran oils, fatty acid, stability, ${ }^{1} \mathrm{H}$ NMR.

\section{INTRODUCTION}

Oil obtained from the rice bran [1] has attracted much interest with many health benefits due to its rich source of natural antioxidant compounds ( $\gamma$-oryzanol, tocopherols and tocotrienols). These compounds are considered to have an important role in preservation of the quality of oils due to their antioxidant activity. Rice bran is extracted or pressed to produce the rice bran oil, $\mathrm{RBO}$ which calls cold-pressed RBO if pressing and no further refinery process has been used. The major component of RBO is triacylglycerols, minor component consist of waxes, mono- and diglycerides, free fatty acids, and other compounds such as tocopherols, tocotrienols, and phytosterols [2]. Those unsaponifiable constituents (USC) of RBO have been reported and found in high levels, include phytosterols (1.5-2\%), oryzanols (1.2-1.8\%), tocopherols and tocotrienols $(0.15-0.2 \%)$ which are bioactive components possessing powerful antioxidative activity [3]-[5].

\footnotetext{
Manuscript received June 3, 2015; revised October 10, 2015. This work was supported in part by the Thai Government under Grant TU007/2558 and funding support from the National Research Council of Thailand (NRCT) code no.TU2558A1060212 (grant no.111903).

J. Singkhonrat and C. Ponchurdchai are with the Department of Chemistry, Faculty of Science and Technology, Thammasat University, Pathumthani 12120 Thailand (e-mail: jirada@tu.ac.th, chutimapcc@gmail.com).
}

The composition of $\gamma$-oryzanol is mixture of phytosteryl ferulates including 4-hydroxy-3-methoxycinnamic acid (ferulate) esters of cycloartenyl ferulate, 24-methylenecycloartanyl ferulate, $\beta$-sitosterol ferulate, and campesterol ferulate that can be separated and quantified by high performance liquid chromatography [6], [7].

In addition, the determination of the proportion of fatty acid in oils and fats can be analyzed by proton nuclear magnetic resonance spectroscopy, ${ }^{1} \mathrm{H}$ NMR spectroscopy in a short period of time and also has a great deal of structural information, required small amount of sample. There are many reports of NMR application for olive oil, walnut oil and other vegetable oils by several authors [8]-[10].

The gas chromatography-mass spectrometry, GC-MS analysis and the integration of signals in the ${ }^{1} \mathrm{H}$ NMR spectra were used for determining the fatty acid compositions and molecular degradation during a year storage. The antioxidant contents and its activity of RBO were also investigated. The aim of this study was to determine the impact of storage temperature on changes in molecular degradation for shelf life of RBOs and to evaluate the stability by monitoring acid, iodine and peroxide values from different storage conditions.

\section{MATERIALS AND METHODS}

\section{A. Chemical Properties of Oil}

Cold-pressed RBO that obtained in 2013 from 2 major rice production regions in Thailand (Lopburi province LRBO and Yasothorn province YRBO) were used 3-6 bottles in this work. Only one bottle of each RBO samples was freshly opened and analysed at time 0 month, RBO- 1 and at time 12 month, RBO-2. The rest of both RBO samples were kept as sealed bottle provided and stored in the darkness at room temperature, RBO-3 and in refrigerator below $5^{\circ} \mathrm{C}, \mathrm{RBO}-4$ throughout the period of 1 year (at time 12 months). Oil sample was evaluated the quality of oil by using classical method to determine acid value, $\mathrm{AV}$, peroxide value, $\mathrm{PV}$ and iodine value, IV. All chemical analyses were carried out according to the association of official analytical chemists, AOAC method.

\section{B. ${ }^{l} H$ NMR Analysis}

Oil sample (approximately $70 \mathrm{mg}$ per sample) was added to $5 \mathrm{~mm}$ NMR tubes and dissolved in $600 \mu \mathrm{L}$ of deuterated chloroform and a small proportion (a drop) of dimethyl sulfoxide- $d 6$. The ${ }^{1} \mathrm{H}$ NMR spectroscopy was performed on a Bruker Avance 400-MHz Spectrometer. The chemical shift was expressed in $\delta$ scale (ppm). All NMR data were analyzed by NMR software "Mnova" from Mestrelab Research and 
solvents were used as internal references.

\section{Fatty acid Composition}

The fatty acid composition was determined by converting oil to methyl esters through esterification reaction by heating oil $(30 \mathrm{~g})$ to $80^{\circ} \mathrm{C}$. Then, added $3 \% \mathrm{wt}$ potassium hydroxide in methanol into reaction solution and stirred this solution for 30 min. After refluxing, the solution was cooled to room temperature and collected the upper layer and then separated glycerol out. The solution was neutralized by warm water and dried with sodium sulfate anhydrous. The methanol was evaporated after filtrate the sodium sulfate anhydrous.

The fatty acid methyl esters were analyzed by using a gas chromatography (Shimadzu GC-2010 plus) equipped with a split/splitless capillary injector and mass spectrometer detector. Analytical separation was achieved on HP-INNOWAX column $(30 \mathrm{~m} \times 0.25 \mathrm{~mm}$ i.d., $0.25 \mu \mathrm{m}$ film thickness). The carrier gas was He, which was supplied at a flow rate of $1.41 \mathrm{~mL} / \mathrm{min}$. The amount injected was $0.1 \mu \mathrm{L}$ and the split ratio was 1:60. Temperature settings were as follows: injector $230^{\circ} \mathrm{C}$; The oven temperature was held at $160^{\circ} \mathrm{C}$ for 5 min. and then programmed to $210^{\circ} \mathrm{C}$ at $4^{\circ} \mathrm{C} / \mathrm{min}$, and held for $6 \mathrm{~min}$ at $210^{\circ} \mathrm{C}$.

\section{Antioxidant Activity Determination}

2,2-Diphenyl-1-picrylhydrazyl (DPPH) free radical scavenging assay [11]: the stock solution $0.24 \mathrm{mg} / \mathrm{mL}$ of DPPH in methanol was prepared and the working solution was obtained by mixing $10 \mathrm{~mL}$ of the stock solution with 45 $\mathrm{mL}$ methanol to obtain a solution having a concentration of about $43 \mu \mathrm{g} / \mathrm{mL}$.

Samples stock solution (10 $\mathrm{mg} / \mathrm{mL}$ in methanol) was further diluted with methanol to obtain several concentrations test sample in a range of $0.1-2.0 \mathrm{mg} / \mathrm{mL}$. Ascorbic acid was used as positive standards. An aliquot $(30 \mu \mathrm{L})$ of these solutions (samples and positive standards) were allowed to react with $170 \mu \mathrm{L}$ of the DPPH working solution for $30 \mathrm{~min}$ in the dark. The absorbance was then measured at $515 \mathrm{~nm}$. Sample concentrations providing $50 \%$ inhibition, $\mathrm{IC}_{50}$ was calculated from the graph plotted between \%inhibitions against sample concentrations. The tests are carried out in triplicate for each sample. The percentage of inhibition was calculated according to (1)

$$
\% \text { Inhibition }=\frac{\text { Acontrol-Asample }}{\text { Acontrol }} \times 100
$$

where

$\mathrm{A}_{\text {control }}=$ absorbance of DPPH solution

$\mathrm{A}_{\text {sample }}=$ absorbance of DPPH reacts with sample

Ferric reducing antioxidant power, FRAP Assay [12]: Assay of reducing power was carried out by potassium ferric cyanide method. Sample solutions were prepared in methanol to have concentrations in a range of $5 \mathrm{mg} / \mathrm{mL}$. Sample $(200 \mu \mathrm{L})$ was mixed with $500 \mu \mathrm{L}$ of phosphate buffer $(0.2 \mathrm{M}$, $\mathrm{pH}$ 6.6) and $500 \mu \mathrm{L}$ of $1 \% \mathrm{w} / \mathrm{v}$ potassium ferricyanide. The mixture was then incubated at $50^{\circ} \mathrm{C}$ for $30 \mathrm{~min}$. The $500 \mu \mathrm{L}$ of $10 \% \mathrm{w} / \mathrm{v}$ trichloroacetic acid was added into the mixture, which was then centrifuged at $3000 \mathrm{rpm}$ for $30 \mathrm{~min}$. Finally, $600 \mu \mathrm{L}$ of the supernatant solution was collected and mixed with $600 \mu \mathrm{L}$ of distilled water and $120 \mu \mathrm{L} 0.1 \%$ w/v ferric chloride and absorbance was measured at $700 \mathrm{~nm}$. Quercetin $(0.01-10 \mu \mathrm{g} / \mathrm{mL})$ was used as a standard and phosphate buffer was used as a blank solution. Result were compared and expressed in quercetin equivalents ( $\mathrm{mg} / \mathrm{g}$ sample).

\section{E. $\gamma$-Oryzanol Analysis}

UV-Vis spectroscopy was applied to determine the oryzanol contents directly from oil sample without any extraction by weighed $10 \mathrm{mg}$ of RBO and dissolved in hexane to make the volume up to $10 \mathrm{~mL}$. The OD was measured in a $1.0 \mathrm{~cm}$ cell at $314 \mathrm{~nm}$ in a Shimadzu UV-240 double beam recording spectrophotometer. The oryzanol content in the oil was calculated by using (2) [7]

$$
\text { oryzanol, } \mathrm{g} \%=\frac{\text { OD of hexane solution }}{\text { weihgt }(\mathrm{g}) \text { of oil }} \times \frac{100}{358.9}
$$

where OD is optical density and 358.9 is the specific extinction coefficient of oryzanol.

\section{F. Statistical Analysis}

The determinations of conventional analysis and NMR analysis were carried out in triplicate and reported as mean values $\pm \mathrm{SD}$. Analysis of covariance (ANACOVA) was carried out on the experimental data by Window and revealed that these significant differences $(p<0.05)$ were between conditions (time and treatment).

\section{RESULTS AND DISCUSSION}

\section{A. Chemical Properties of Oil}

(a)

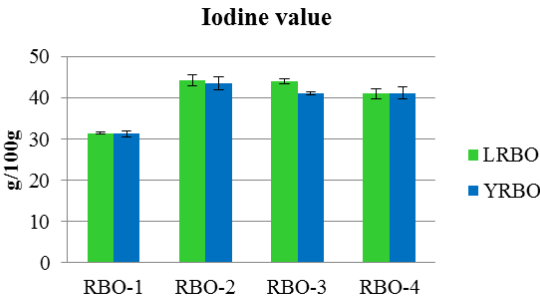

(b)

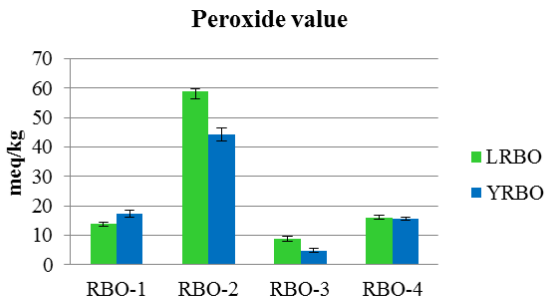

(c)

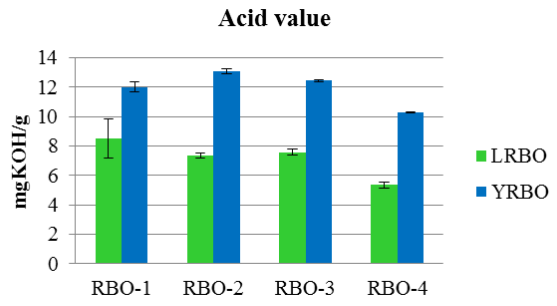

Fig. 1. (a) Iodine values, (b) acid values and (c) peroxide values of L-RBO and Y-RBO in different storage conditions: freshly opened RBO-1; opened over 12 months RBO-2; sealed at room temperature over 12 months RBO-3; sealed below $5^{\circ} \mathrm{C}$ over 12 months RBO-4

According to different storage conditions, Fig. 1a showed 
that the IV of both RBOs after one-year storage strangely insignificantly different, which may be subjected by complexity of crude cold-pressed RBO matrixes. LRBO-2, LRBO-3 and L-RBO-4 observed the IV of $44.19 \pm 1.32$, $43.98 \pm 0.56$ and $41.06 \pm 1.19 \mathrm{~g} / 100 \mathrm{~g}$, respectively. YRBO-2, YRBO-3 and YRBO-4 observed the IV of $43.56 \pm 1.55$, $41.13 \pm 0.29$ and $41.16 \pm 1.42 \mathrm{~g} / 100 \mathrm{~g}$, respectively. When the different storage conditions were investigated through the year, all samples were appeared with sediment and colloid of micro particles and suggested to free the unsaturated fatty chains and unbound double bonds. That was suggested as a reason that both freshly opened bottles obtained lower IV in LRBO-1 and YRBO-1 which observed the IV of 31.45 \pm 0.18 and $31.24 \pm 0.73 \mathrm{~g} / 100 \mathrm{~g}$, respectively.

Freshly opened bottle of LRBO-1 and YRBO-1 observed the PV of $14.07 \pm 0.23$ and $17.32 \pm 1.14 \mathrm{meq} / \mathrm{kg}$, respectively. From Fig. 1b, after year storage, both RBO obtained significantly difference of peroxide value except YRBO obtained below $5^{\circ} \mathrm{C}$ is not significant difference from fresh oil. LRBO-2, LRBO-3 and LRBO-4 observed the PV of $58.76 \pm 0.83,8.85 \pm 0.63$ and $15.84 \pm 0.81 \mathrm{meq} / \mathrm{kg}$, respectively. YRBO-2, YRBO-3 and YRBO-4 observed the PV of $44.21 \pm 2.35,4.82 \pm 0.78$ and $15.52 \pm 0.50 \mathrm{meq} / \mathrm{kg}$, respectively. The oil exposed to the air obtained higher peroxide value due to higher oxidation rate with oxygen molecules in the direct air exposure, but without air exposure oil storage below $5^{\circ} \mathrm{C}$ has lower peroxide value than storage at room temperature. It can be indicate that after one year storage of oil as sealed bottle is not affected to peroxide value significantly $(p<0.05)$. In addition, $\mathrm{AV}$ in Fig. 1c of both oils in all conditions is not significant difference $(p<0.05)$. LRBO and YRBO observed the AV range of 5.34-8.52 and 12.00-13.29 $\mathrm{mgKOH} / \mathrm{g}$, respectively. It can be suggested that after one year storage of oil is not affected to hydrolysis according to relatively stable acid value in every condition.

\section{B. Fatty Acid Composition}

TABLE I: THE EQUATIONS FOR DETERMINING A FATTY ACID COMPOSITION BY ${ }^{1} \mathrm{H}$ NMR TECHNIQUE

\begin{tabular}{lll}
\hline & Method A & Method B \\
\hline $\mathrm{S}(\%)$ & $100[\mathrm{~B} /(\mathrm{A}+\mathrm{B})]$ & $100[2 \mathrm{~B} / 3 \mathrm{D}]$ \\
$\mathrm{O}(\%)$ & $100[(\mathrm{E} / \mathrm{D})-2[\mathrm{~B} /(\mathrm{A}+\mathrm{B})]]$ & $100[(3 \mathrm{E}-4 \mathrm{~B}) / 3 \mathrm{D}]$ \\
$\mathrm{L}(\%)$ & $100[(\mathrm{C} / 2 \mathrm{D})-(\mathrm{E} / \mathrm{D})+[\mathrm{B} /(\mathrm{A}+\mathrm{B})]]$ & $100[\mathrm{Ln}+\mathrm{L}+\mathrm{S}]^{*}$ \\
$\mathrm{Ln}(\%)$ & $100[1-(\mathrm{C} / 2 \mathrm{D})]$ & $100[(4 \mathrm{~A}+4 \mathrm{~B}-3 \mathrm{C}) / 6 \mathrm{D}]$ \\
\hline
\end{tabular}

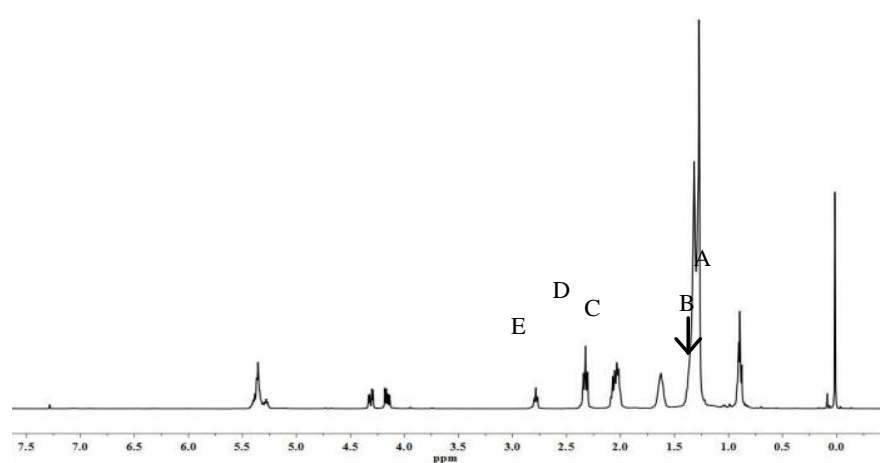

Fig. 2. $400 \mathrm{MHz}{ }^{1} \mathrm{H}$ NMR spectrum of LRBO-4.

The determination of the proportions of oleic, $\mathrm{O}$, linoleic, $\mathrm{L}$, linolenic, Ln and saturated, S acyl groups in RBO carried out by using the equations in Table I. The parameter A-E is the integration of some signals of the spectra as show in Fig. 2. Method A [13] based on proportional methyl group in sample and method B [14] based on the methylenic hydrogen atom in $\alpha$ position. From Table II, it can be observed that ${ }^{1} \mathrm{H}$ NMR technique was analyzed and calculated the intensity for the unsaturated fatty acid compositions of RBO samples and GC-MS technique was provided all the saturated fatty acid compositions of the RBO samples. When compared with GC-MS technique, ${ }^{1} \mathrm{H}$ NMR can be made in a few minutes and without any chemical manipulation of sample. Therefore, equation in method $\mathrm{A}$, which obtained with reasonable standard deviations $(<0.7)$, was used for comparing the stability of RBOs and the results were analyzed from their intensity according to assigned ${ }^{1} \mathrm{H}$ NMR spectra, shown in Fig. 3.

\section{Fatty acid composition of LRBO}

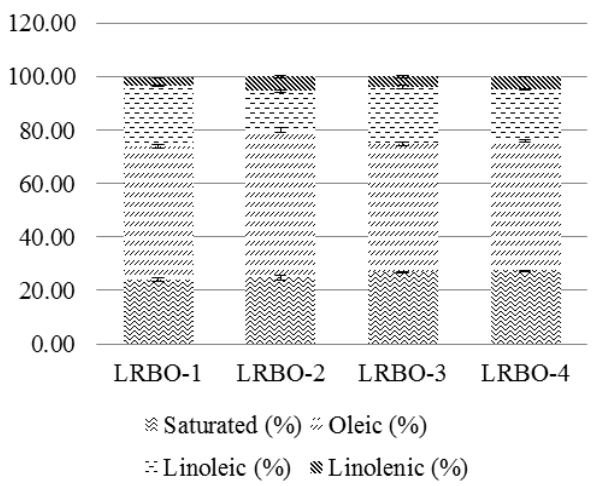

Fatty acid composition of YRBO

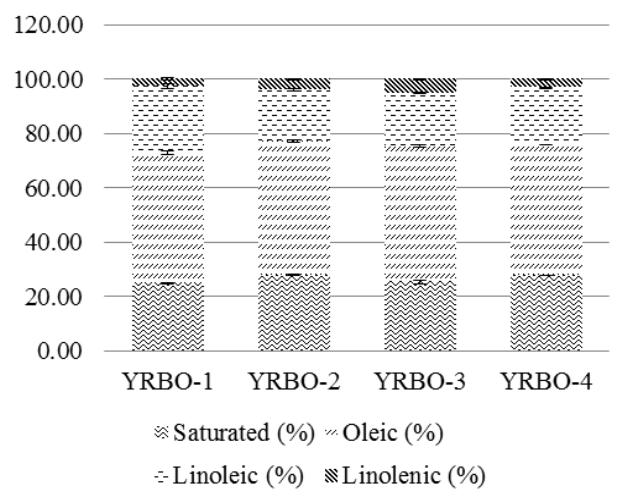

Fig. 3. The fatty acid composition of RBO in different storage condition derived from ${ }^{1} \mathrm{H}$ NMR spectra and calculated by method A.

LRBO samples revealed no impact of the storage condition by keeping the fatty acid profiling consistently, whereas YRBO sample, observed that sealed bottles at room temperature in the dark, showed the best condition on steadying the level of unsaturated fatty acid composition significantly over 12-month storage.

\section{Antioxidant Activity}

RBOs, kept as sealed bottle below $5^{\circ} \mathrm{C}$, were screened to determine its free radical scavenging activities. Two different methods were used to test the antioxidant activity of the extract, including FRAP assay and DPPH radical scavenging assay. From Table III, LRBO-4 and YRBO-4 showed good DPPH radical scavenging activities with $\mathrm{IC}_{50}$ of $0.647 \pm 0.02$ and $0.663 \pm 0.02 \mathrm{mg} / \mathrm{mL}$ and FRAP of $0.42106 \pm 0.002$ and $0.37471 \pm 0.002$ quercetin equivalents $\mathrm{g} / \mathrm{g}$, respectively. 
TABLE II: FATTY ACID COMPOSITION OF LRBO-4 AND YRBO-4

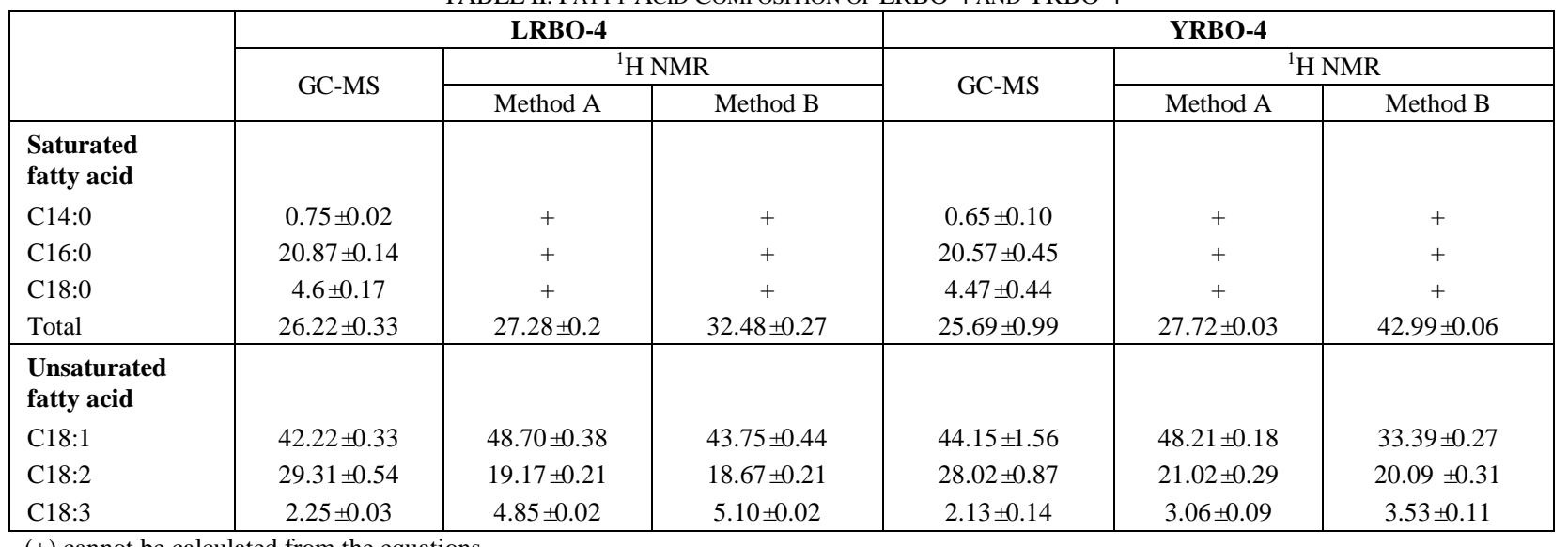

- (+) cannot be calculated from the equations.

- C14:0-myristic acid, C16:0-palmitic acid, C18:0-stearic acid, C18:1-oleic acid, C18:2-linoleic acid, C18:3-linolenic acid

These result showed that LRBO-4 had slightly better antioxidation activities than YRBO-4 with higher value $(2.47 \%)$ in $\mathrm{IC}_{50}$ of $\mathrm{DPPH}$ and lower quercetin equivalent $(12.4 \%)$ in FRAP.

\begin{tabular}{|c|c|c|}
\hline Sample & $\begin{array}{c}\text { DPPH }^{1} \\
\text { IC }_{50}(\mathrm{mg} / \mathrm{ml})\end{array}$ & $\begin{array}{c}\text { FRAP }^{2} \\
\text { Quercetin Equivalent (g/g) }\end{array}$ \\
\hline LRBO-4 & $0.647 \pm 0.02$ & $0.42106 \pm 0.002$ \\
\hline YRBO-4 & $0.663 \pm 0.02$ & $0.37471 \pm 0.002$ \\
\hline
\end{tabular}

\footnotetext{
${ }^{1} \mathrm{IC}_{50}=$ concentration that can reduce Free radical from $100 \%$ to $50 \%$

${ }^{2}$ Quercetin Equivalent $(\mathrm{g} / \mathrm{g})$ is amount of quercetin that gives antioxidant property equivalent to the antioxidant property of sample.
}

The differences in the oxidation activity of the oils (LRBO and YRBO) may be attributed to the different processing and refining conditions applied. It was noticed that rice bran (DPPH activity in $\mathrm{EC}_{50}$ of $0.56 \mathrm{mg} / \mathrm{mL}$ [15]) possessed a greater activity than one-year old cold-pressed rice bran oils. This may be due to the fact that natural polyphenols and other antioxidants in oil can vary with the conditions of extraction and processing and can be decreased to a greater extent while following the pressing methods for obtaining commercial products and period of storage.

\section{D. $\gamma$-Oryzanol Contents}

The samples of RBO were observed the level of antioxidant contents. According to UV-Vis spectroscopy technique, both oil samples (LRBO and YRBO) obtained a high oryzanol contents. The different storage condition indicated the effect of oryzanol contents as shown in Table IV. RBO which is kept as sealed bottle below $5^{\circ} \mathrm{C}$ revealed higher level of oryzanol than other condition.

TABLE IV: ORYZANOL CONTENTS OF RBO

\begin{tabular}{ccc}
\hline & \multicolumn{2}{c}{ \%Oryzanol } \\
\hline & Lopburi, $\mathbf{L}$ & Yasothorn, $\mathbf{Y}$ \\
\hline RBO-2 & $1.39 \pm 0.02$ & $1.69 \pm 0.05$ \\
RBO-3 & $1.50 \pm 0.21$ & $1.72 \pm 0.03$ \\
RBO-4 & $1.57 \pm 0.05$ & $1.89 \pm 0.10$ \\
\hline
\end{tabular}

\section{CONCLUSION}

The different storage conditions affected to the stability of cold-pressed rice bran oil over a year. On the other hand, the comparison of freshly opened and one-year old sealed bottle samples had shown indifferent in acid value peroxide value and iodine value. In molecular level, the fatty acid composition of oil by ${ }^{1} \mathrm{H}$ NMR technique can be alternative method to GC-MS technique also showed slightly decreasing on unsaturated fatty acid composition in all condition over a year storage. $\mathrm{RBO}$ in sealed bottle and storage below $5^{\circ} \mathrm{C}$ over a year showed a good level of antioxidant activity and oryzanol contents. A year shelf-life of cold-pressed RBO is suggested and appreciated for consuming as an alternative source of antioxidants.

\section{ACKNOWLEDGMENT}

The authors are thankful to Department of Chemistry, Faculty of Science and Technology, Thammasat University and also gratefully acknowledge the partial support provided by Central Scientific Instrument Center (CSIC) Faculty of Science and Technology Thammasat University. Contract No $001 / 2556$.

\section{REFERENCES}

[1] S. A. Antunes, M. Lanza, and H. Hense, "Rheological properties of rice bran (Oryza sativa L.) oils processing and soapstock distillation residue," Industrial Crops and Products, vol. 46, pp. 111-116, April 2013.

[2] E. L. Bakota, J. K. Winkler-Moser, H.-S. Hwang, M. J. Bowman, D. E. Palmquist, and S. X. Liu, "Solvent fractionation of rice bran oil to produce a spreadable rice bran product," European Journal of Lipid Science and Technology, vol. 115, no. 8, pp. 847-857, August 2013.

[3] S. Mezouari and K. Eichner, "Comparative study on the stability of crude and refined rice bran oil during long-term storage at room temperature," European Journal of Lipid Science and Technology, vol. 109, no. 3, pp. 198-205, March 2007.

[4] R. Renuka Devi and C. Arumughan, "Phytochemical characterization of defatted rice bran and optimization of a process for their extraction and enrichment," Bioresour Technol, vol. 98, no. 16, pp. 3037-3043, November 2007.

[5] R. Dhara, P. Dhar, and M. Ghosh, "Dietary effects of pure and diacylglycerol-rich rice bran oil on growth pattern and lipid profile of rats," Journal of Oleo Science, vol. 61, no. 7, pp. 369-375, 2012.

[6] M. Friedman, "Rice Brans, rice bran oils, and rice hulls: composition, food and industrial uses, and bioactivities in humans, animals, and 
cells," Journal of Agricultural and Food Chemistry, vol. 61, no. 45, pp. 10626-10641, November 2013.

[7] A. G. Gopala Krishna, K. H. Hemakumar, and S. Khatoon, "Study on the composition of rice bran oil and its higher free fatty acids value," Journal of the American Oil Chemists' Society, vol. 83, no. 2, pp. 117-120, February 2006.

[8] R. Sacchi, F. Addeo, and L. Paolillo, " ${ }^{1} \mathrm{H}$ and ${ }^{13} \mathrm{C}$ NMR of virgin olive oil. An overview," Magnetic Resonance in Chemistry, vol. 35, no. 13, pp. S133-S145, December 1997.

[9] Y. Miyake, K. Yokomizo, N. Matsuzaki, "Rapid determination of iodine value by ${ }^{1} \mathrm{H}$ nuclear magnetic resonance spectroscopy," Journal of the American Oil Chemists' Society, vol. 75, no. 1, pp. 15-19. 1998.

[10] M. D. Guillén and P. S. Uriarte, "Study by ${ }^{1} \mathrm{H}$ NMR spectroscopy of the evolution of extra virgin olive oil composition submitted to frying temperature in an industrial fryer for a prolonged period of time," Food Chemistry, vol. 134, no. 1, pp. 162-172, September 2012.

[11] W. Brand-Williams, M. E. Cuvelier, and C. Berset, "Use of a free radical method to evaluate antioxidant activity," LWT - Food Science and Technology, vol. 28, no. 10, pp. 25-30, 1995.

[12] A. Yildirim, A. Mavi, and A. A. Kara, "Determination of antioxidant and antimicrobial activities of Rumex crispus L. extracts," Journal of Agricultural and Food Chemistry, vol. 49, no. 8, pp. 4083-4089, August 2001.

[13] M. D. Guillén and Ainhoa Ruiz, "Rapid simultaneous determination by proton NMR of unsaturation and composition of acyl groups in vegetable oils," European Journal of Lipid Science and Technology, vol. 105, no. 11, pp. 688-696, 2003.

[14] A. Agiomyrgianaki, J. Sedman, F. R. Van de Voort, and P. Dais, "Cis and trans components of lipids: Analysis by ${ }^{1} \mathrm{H}$ NMR and silver shift reagents," European Journal of Lipid Science and Technology, vol. 114, no. 5, pp. 504-509, January 2012.

[15] T. Laokuldilok, Charles F. Shoemaker, S. Jongkaewwattana, and V. Tulyathan, J. Agric. Food Chem., vol. 59, pp. 193-199, 2011.

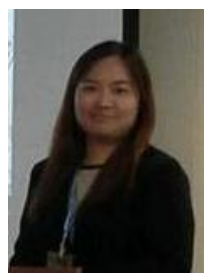

C. Ponchurdchai was born in Thailand on July 20, 1990. She is pursuing her master degree of chemistry, from Thammasat University, Patumthani, Thailand since 2012. She received her B.Sc. degree in chemistry, Thammasat University, Patumthani, Thailand in 2012.

She was a teaching assistant of Fundamental Chemistry Laboratory and Chemistry1 Laboratory at Thammasat University during 2013-2014.

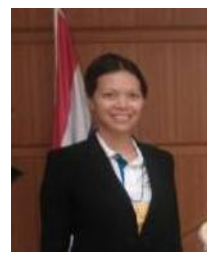

J. Singkhonrat was born in Thailand on February 23, 1976. She received her $\mathrm{PhD}$ degree in synthetic organic chemistry, Cardiff University, Wales, UK in 2005. She obtained her MSc degree in advanced chemical technology, UMIST, Manchester, UK in 2000. And she got her BSc degree in chemistry, Mahidol University, Bangkok, Thailand in 1998.

Jirada was an exchange student and worked as Research Assistant at NRC-Canada in 1998-1999. She carried out work replacement as a medicinal chemist during her $\mathrm{PhD}$ with biofocus in UK during 2003-2004. She is currently an Assistant Professor in industrial chemistry at Department of Chemistry, Faculty of Science and Technology, Thammasat University, Pathumthani Thailand. Her recent publication are listed: 1) Chuenkamol Khongphow, Somchintana Puttamat, Jatuporn Theerakul and Jirada Singkhonrat, Characterization of poly(glycerol-succinate) oligomers as bio-based non-ionic surfactants by nuclear magnetic resonance and mass spectrometry, Colloids and Surfaces A: Physicochemical and Engineering Aspects, 468, 2015, 301-308. 2) Jirada Singkhonrat, Separation processes for Chemist, 2014, Thammasat University, Pathumthani, pressed in Thai. 3) N. Singtongrat, S. Vadhanasin and J. Singkhonrat, Hydroxychavicol and Eugenol Profling of Betel Leaves from Piper betel L. Obtained by Liquid-Liquid Extraction and Supercritical Fluid Extraction, Kasetsart J. (Nat. Sci.), 47(4), 2013, 614-623. Her current interest focuses on industrial chemistry, organic synthesis, process chemistry, green industry with bio-based chemicals.

Jirada Singkhonrat is a member of Thai Chemical Society, where she served as a board member during 2008-2012. She was selected as Young Scholar of PACIFICHEM2010. 